\title{
Comparative Biochemistry
}

National Cancer Institute

\section{Source}

National Cancer Institute. Comparative Biochemistry. NCI Thesaurus. Code C18715.

The study of the similarities and differences between different living organisms of the biological and physiological chemistry of the organisms. Used for the scientific discipline or the biochemical processes themselves. (from PSY94) 